\author{
Andrii Doronin $^{1 凶}$, Olena Rybchak ${ }^{2}$, Olena Polishchuk ${ }^{2}$ \\ ${ }^{1}$ National Academy of Agrarian Sciences of Ukraine \\ ${ }^{2}$ Uman National University of Horticulture
}

\title{
Crop production as the basis of the production of alternative fuels
}

\begin{abstract}
Summary. In the article were analyzed tendencies of market development of plant growing in Ukraine, which provides not only food security of country, but also agroproducts export. The high profitability of corn, sunflower, soybean and rapeseed growing is stimulating producers their area sown to increase. The perspectives of the use of sugar beets and their processed products, wheat and corn for the alternative fuel production were discussed in the paper. The suggestions how to ensure the competitiveness of bioethanol production using processed sugar beets in Ukraine were discussed; the processing of molasses for bioethanol appeared to be the most cost-effective.
\end{abstract}

Key words: ecology, competitiveness, sugar beets, sugar, molasses, bioethanol

\section{Introduction}

Crop production always was and remains a main industry of the agricultural sector of Ukraine, which provides not only food security of country, but also agroproducts export. From this industry development is depends not only population providing of food products of plant origin, but also animal products. However, in view of an urgent problem of providing our country with price-affordable energy carriers, it becomes appropriate to speed up the alternative fuel production.

Alongside with sugar production, and as the country needs energy carriers very much, it is quite relevant to use sugar beets and the output of sugar beet processing for the production of bioethanol as an alternative fuel. A considerable contribution to the development of the competitiveness of sugar beet companies, including the explanation of the ways of its enhancement, was made by O. Varchenko, H. Kaletnik, M. Kodenska, M. Royik, P. Sabluk, O. Shpychak, V. Bondar, A. Fursa and others.

The purpose of the research is to develop practical recommendations which help ensure the competitive manufacturing of bioethanol using the output from crop production.

\footnotetext{
andredor@meta.ua
} 


\section{Research methodology}

The data received from the State Statistics Department of Ukraine and the author's own calculations were used in the process of writing an article. The methods of system analysis and logic generalization were used to study the experience of bioethanol production from crop produce; the comparative analysis was used in the process of analyzing the statistical information; the monographic method helped substantiate the necessity of diversification of the products of sugar beet industry, induction and deduction facilitated the summarizing of the results of the research; an abstract logic method was applied to make conclusions and proposals.

\section{Results of the research}

In the early of 1990s in Ukraine, during the transition to market relations for all sectors of the economy were conditions created of free pricing and for agriculture reference prices introduced, which grew much slower than on goods and services that are consumed in agriculture, which disparity resulted in prices does not in favor of farmers. This, in turn, was influenced on the structure of sown areas of agricultural crops - industrial crops increases as more profitable.

Thus in the structure of agricultural crops sown area for 2001-2016 years have a noticeable increase of industrial crops share in total sown area - 13.5\% in 2001 to $32.3 \%$ in 2016 (Table 1) ${ }^{1}$. Share of industrial crops is increasing in total sown area was due to the expansion of sown areas under sunflower $-9.0 \%$ in 2001 to $22.1 \%$ in 2016 and the emergence from the 2008 soybeans and rapeseed crops - to $6.9 \%$ and $1.7 \%$ in 2016 respectively.

The share of grain and leguminous plants decreased $-55.8 \%$ in 2001 to $53.6 \%$ in 2016. Including the share of food crops was decreased $-32.8 \%$ in 2001 to $24.9 \%$ in 2016 , while the share of grain forage crops was grown $-23.0 \%$ in 2001 to $28.7 \%$ in 2016.

This is noticeable a significant decrease of forage crops share $-22.8 \%$ in 2001 to $7.2 \%$ in 2016, which negatively affected on the livestock farming development in Ukraine. In the structure of sown area is remains almost unchanged potato and vegetable and melon crops $-7.9 \%$ in 2001 to $6.9 \%$ in $2016^{2}$.

In the agricultural producers sown areas structure was formed under many factors influencing. The main ones are: structure of agricultural lands, their quality specialization, product demand, and availability of means of production and labor resources, and climatic conditions.

Rational structure of sown areas is provides production of the required amounts of grain, industrial and forage crops, potatoes, vegetables in the required range, and all cultures - good predecessor and is promotes the appropriate agronomic and economic conditions, and on this basis - enhances of productivity increasing. This structure is

\footnotetext{
${ }^{1}$ Sown areas of agricultural crops under the harvest, Statistical Bulletins of years 2015, 2016, State Statistics Committee of Ukraine, Kyiv.

${ }^{2}$ Ibidem.
} 
Table 1. Structure of agricultural crops sown area in Ukraine in the period 2001-2016 (farms of all categories)

\begin{tabular}{|c|c|c|c|c|c|}
\hline \multirow{2}{*}{ Agricultural crop } & \multicolumn{5}{|c|}{ Structure of sown area by the years (\%) } \\
\hline & 2001 & 2005 & 2014 & 2015 & 2016 \\
\hline Grain and leguminous crops, including & 55.8 & 57.6 & 54.3 & 54.7 & 53.6 \\
\hline food & 32.8 & 30.3 & 24.0 & 27.2 & 24.9 \\
\hline wheat (winter and spring) & 25.5 & 25.6 & 22.3 & 25.5 & 23.2 \\
\hline rye (winter and spring) & 3.3 & 2.4 & 0.7 & 0.6 & 0.5 \\
\hline rice & 0.1 & 0.1 & 0 & 0.1 & 0.1 \\
\hline millet & 1.3 & 0.5 & 0.4 & 0.4 & 0.4 \\
\hline buckwheat & 2.6 & 1.6 & 0.5 & 0.5 & 0.6 \\
\hline haricot & 0.1 & 0.1 & 0.1 & 0.1 & 0.1 \\
\hline grain fodder & 23.0 & 27.3 & 30.3 & 27.5 & 28.7 \\
\hline barley (winter and spring) & 14.7 & 17.3 & 11.1 & 10.4 & 10.6 \\
\hline corn & 4.6 & 6.6 & 17.2 & 15.2 & 15.9 \\
\hline oat & 2.1 & 1.8 & 0.9 & 0.8 & 0.8 \\
\hline leguminous (without haricot) & 1.4 & 1.5 & 0.8 & 0.9 & 1.1 \\
\hline sorghum & 0.1 & 0.1 & 0.3 & 0.2 & 0.3 \\
\hline Industrial crops, including & 13.5 & 20.2 & 31.0 & 31.1 & 32.3 \\
\hline sunflower & 9.0 & 14.4 & 19.3 & 19.0 & 22.1 \\
\hline sugar beet (factory) & 3.5 & 2.5 & 1.2 & 0.9 & 1.1 \\
\hline soybean & - & - & 6.6 & 8.0 & 6.9 \\
\hline rapeseed (winter and spring) & - & - & 3.2 & 2.5 & 1.7 \\
\hline $\begin{array}{l}\text { Potatoes and vegetable and melon crops, } \\
\text { including }\end{array}$ & 7.9 & 7.8 & 7.0 & 6.8 & 6.9 \\
\hline potato & 5.7 & 5.8 & 4.9 & 4.8 & 4.9 \\
\hline vegetables & 1.8 & 1.8 & 1.7 & 1.6 & 1.6 \\
\hline Fodder root & 22.8 & 14.4 & 7.7 & 7.4 & 7.2 \\
\hline
\end{tabular}

Source: Sown areas of agricultural crops under the harvest, Statistical Bulletins of years 2015, 2016, State Statistics Committee of Ukraine, Kyiv.

provide an opportunity of the most productive using of farmland, opportunities for the introduction of regular rotation creating, because each culture is need the good predecessor. In recent years, the structure of rotation was increased the share of crops, demand of which has increased (sunflower, corn, soybean), which led to infringement of evidence-based rotation. Failure to comply of crop rotation, simplified system of soil tillage and plant care has led to a deterioration of phytosanitary state of agricultural crops and pesticide load increased, consequently, that adversely affects not only on environmental protection, but also on the safety of people. 
In Ukraine the socio-economic crisis had a negative impact both on the development of agriculture in general and crop production ${ }^{3}$.

If in 1990, in Ukraine, the production of cereals and leguminous was amounted of 51.0 million t, in 2000, only 24.4 million t, respectively, have a reduction of sugar beet production - from 44.2 million $t$ in 1990 to 13.2 million $t$ in 2000, but in sunflower production seeing a rise - from 2.5 million $t$ in 1990 to 3.4 million $t$ in 2000 . And only in later years, grain production is growing rapidly: from 39.7 million $t$ in 2001 to 60.1 million $t$ in 2015 , or $51.4 \%$. During this period it should be noted the production of corn growth in 6.4 times - up to 23.3 million $t$ in 2015 among cereals.

At the same time by the $2001-2015$ rye production is reduced to $78.5 \%$ - to 391.1 thousand $t$, millet on $20.0 \%$ - to 213.2 thousand $t$, buckwheat on $67.0 \%$ - to 128.1 thousand $t$, barley on $18.6 \%$ - up to $8,288.4$ thousand $t$, oat on $56.2 \%$ - to 488.5 thousand $t$, leguminous on $39.3 \%$ - to 502.1 thousand $t$.

We are observing a significant increase in sunflower production - from 2.2 million $\mathrm{t}$ in 2001 to 11.1 million $\mathrm{t}$ in $\mathbf{2 0 1 5}$, or 5 times, soybean in 53.2 times - to 3.9 million $\mathrm{t}$, rapeseed in 12.9 times - to 1.7 million t. Potato production is growing dynamically on $20.2 \%$ - to 20.8 million $t$ in 2015 and also vegetables on $56.0 \%$ - to 9.2 million t. Production of fodder root is decreases gradually over the years on $19.8 \%$ - to 6.1 million $t$ in $2015^{4}$.

Compliance elements of crops growing technology, the main ones are the nutrition of plants and protect them from pests, diseases and weeds with soil and climatic conditions of Ukraine is provided increasing of these crops productivity during this period: cereals and leguminous on $51.7 \%$ - to 4.11 t/ha in 2015 , in particular of rye on $25.1 \%$ - to $2.59 \mathrm{t} / \mathrm{ha}$, rice on $45.9 \%$ - to $5.34 \mathrm{t} / \mathrm{ha}$, buckwheat on $49.2 \%$ - to $1.0 \mathrm{t} / \mathrm{ha}$, corn on $76.2 \%$ - to $5.71 \mathrm{t} /$ ha, oat on $16.0 \%$ - to $2.32 \mathrm{t} / \mathrm{ha}$, sunflower in 2.3 times - to $2.16 \mathrm{t} / \mathrm{ha}$, sugar beet in 2.4 times - to $43.58 \mathrm{t} / \mathrm{ha}$, soybean on $82.2 \%$ - to $1.84 \mathrm{t} / \mathrm{ha}$, rapeseed in 2.1 times - to 2.59 t/ha, potato on $49.3 \%$ - to 16.14 t/ha, vegetables on $67.3 \%$ - to 20.61 $\mathrm{t} / \mathrm{ha}$, fodder root crops on $19.6 \%$ - to $28.86 \mathrm{t} / \mathrm{ha}^{5}$.

So, by the 2001-2015 years are seeing the growth in production of some agricultural crops, both by their share increase in the total sown area, and thus their yield increase, including: sunflower, soybean, rapeseed. Due to only crop yields growth is increased production of wheat, sugar beet, potatoes and vegetables. It is seeing production of rye, buckwheat, barley, oat and fodder root decreases only of their sowing areas reducing. Decrease of legumes production is occurred as by reducing of their share in the total sown area, and thus in their productivity decrease.

\footnotetext{
${ }^{3}$ Plant growing of Ukraine, Statistical Digest of years 2005, 2015, State Statistics Committee of Ukraine, Kyiv.

${ }^{4}$ Sown areas of agricultural crops under the harvest, Statistical Bulletins of years 2001, 2015, State Statistics Committee of Ukraine, Kyiv 2001.

${ }^{5}$ Plant growing of Ukraine, Statistical Digest of years 2005, 2015, State Statistics Committee of Ukraine, Kyiv.
} 
It should be noted that in recent years in structure of areas under crops a significant share is occupy grain and leguminous crops (2016-53.6\%), including wheat (2016 $-23.2 \%)$, barley $(2016-10.6 \%)$, corn $(2016-15.9 \%)$.

Thus, in Ukraine there are all preconditions for increasing the production of grain crops that provide not only food security but also export products.

It should be noted extensive development of trade relations of Ukraine in the market of grain products industry. The main agri-food products of Ukrainian exports to European Union countries are raw production of plant growing (seed of cereal and oil crops), crude sunflower and other oils.

Taking into attention a favorable conjuncture of external sale markets and prices rising, farmers are increasing sown area under the industrial crops in Ukraine. In particular, the high profitability level of sunflower, soybean and rapeseed is stimulating producers their area sown increases, compared with other crops (Table 2$)^{6}$.

Table 2. Economic efficiency of main agricultural crops production in Ukraine in the period 2008-2016 (agricultural enterprises)

\begin{tabular}{|l|c|c|c|c|c|c|c|}
\hline Agricultural crop & 2008 & 2010 & 2012 & 2013 & 2014 & 2015 & 2016 \\
\hline Wheat & 17.6 & 9.6 & 11.8 & 2.4 & 28.0 & 36.4 & 31.7 \\
\hline Barley & 19.8 & -0.4 & 11.4 & 0.6 & 18.3 & 28.3 & 25.4 \\
\hline Corn & 10.6 & 29.9 & 19.8 & 1.5 & 26.2 & 50.3 & 45.7 \\
\hline Seed of sunflower & 18.4 & 64.7 & 45.8 & 28.5 & 36.5 & 80.5 & 63.0 \\
\hline Sugar beet & 7.1 & 16.7 & 15.7 & 2.7 & 17.9 & 28.2 & 24.3 \\
\hline Soybean & 1.3 & 16.4 & 23.4 & 15.8 & 34.5 & 38.6 & 52.0 \\
\hline Rapeseed & 51.3 & 26.6 & 21.4 & 8.6 & 29.2 & 44.3 & 45.0 \\
\hline Potatoes & 7.9 & 62.1 & -21.5 & 23.0 & 9.2 & 24.2 & -3.2 \\
\hline
\end{tabular}

Source: Basic economic indicators of agricultural production in agricultural enterprises, Statistical Bulletins of years 2008, 2010, 2012, 2013, 2014, 2015, 2016, State Statistics Committee of Ukraine, Kyiv.

In 2012-2013 years the reason of the loss of efficiency of grain industry is the lack of development of agricultural market infrastructure and sales of grain, the lack of an effective mechanism of state regulation of pricing on grain products in conditions of both overproduction of grain and harvest failure, high level of credit rates and inadequate of budgetary support. In the modern conditions, government regulation of the grain market in Ukraine does not play the stimulus role in relation to grain production and is not able to responding effectively on the challenges of the global economy.

It is advisable on a national level is create and involve the effective mechanisms for regulation of market products of plant growing. For stabilize prices of industry products

\footnotetext{
${ }^{6}$ Basic economic indicators of agricultural production in agricultural enterprises, Statistical Bulletins of years 2008, 2010, 2012, 2013, 2014, 2015, 2016, State Statistics Committee of Ukraine, Kyiv.
} 
the state must carry purchasing and commodity interventions, coordinate and harmonize the pricing policy at the national and international markets.

Raw materials orientation of Ukrainian exports makes Ukraine's position on foreign markets is vulnerable, as the demand on raw goods is unstable and characterized by significant variability price.

It should be noted that in Ukraine export of crops is increases, and the largest share of import from the EU is takes meat and food offal, in the future this tendency could adversely influence on the development of the domestic livestock industry.

Hence, the main directions of adaptability of crop production in modern conditions increasing are: placement of agricultural crops in favorable soil and climatic conditions, creation of varieties and hybrids, adapted to the natural conditions of Ukraine, plant growing industry is transfer to post-industrial development models, raw material base for bioenergy is provide, forage base for livestock is create, development of organic production, structuration of market production of plant growing.

To achieve these goals it is necessary to solve the issue of soil fertility increasing by complex organizational and technological measures introducing, such as: the use of research based crop rotation at cultures growing, the orientation on organic fertilization system, the efficiency of fertilizer application by optimizing the dose, timing and methods of application in the soil improving, soil tillage technologies development, reducing the negative impact of plant protection chemicals as the plant itself, and the useful microflora of soil.

Farming is providing by the adapted varieties and hybrids of agricultural plants with higher productivity and also their environmental resistance to conditions of the environment, the organization of seed production of agricultural crops is requires in Ukraine. Thus even, adapted varieties and hybrids to weather and environmental conditions cannot always provide the high productivity of agricultural crops through the process of global warming on our planet.

Application of postindustrial models of crop production industry is includes the development and implementation: resource saving bioadaptive technologies of agricultural crops growing, integrated plant protection, methods of optimization the process of growth and development of plants, with climate change considering and on the principles of precision farming.

In Ukraine the developed sugar beet production is a universal basis for the production of bioethanol (Table 3).

The greatest output of bioethanol per unit area at the appropriate level of yield can be obtained from the sugar beets. However, in the processing of sugar beet into sugar we get the molasses, and depending on its quality the output of bioethanol from $1 \mathrm{t}$ can be $0.222-0.237 \mathrm{t}$.

Considering the world experience of using sugar beets for bioethanol production as an alternative fuel, it would be appropriate to implement it at the sugar processing factories of Ukraine. The need to diversify a sub-complex of sugar beet production is determined not only by the country's high dependence on energy resource import, but also by the necessity to have additional facilities to process the excess production, tak- 
Table 3. The calculation of the output of bioethanol from various types of raw materials by the different yields

\begin{tabular}{|c|c|c|c|}
\hline \multirow[t]{2}{*}{ Raw } & \multicolumn{2}{|c|}{$\begin{array}{l}\text { The output of bioethanol in calculating } \\
\text { per } 1 \text { ha depending on the yields of culture (t) }\end{array}$} & \multirow{2}{*}{$\begin{array}{l}\text { Prime cost of } 1 \text { I } \\
\text { of bioethanol } \\
\text { (USD) }\end{array}$} \\
\hline & yield & output of bioethanol & \\
\hline \multirow{3}{*}{ Sugar beets (crude juice) } & 40.0 & $2.96-3.16$ & \multirow{3}{*}{1.14} \\
\hline & 50.0 & $3.70-3.95$ & \\
\hline & 60.0 & $4.44-4.74$ & \\
\hline \multirow{3}{*}{$\begin{array}{l}\text { Molasses (processing of sugar } \\
\text { beet into sugar) }\end{array}$} & 1.56 & $0.35-0.37$ & \multirow{3}{*}{0.74} \\
\hline & 1.95 & $0.43-0.46$ & \\
\hline & 2.34 & $0.52-0.55$ & \\
\hline \multirow{3}{*}{ Wheat } & 3.0 & $0.71-0.93$ & \multirow{3}{*}{1.04} \\
\hline & 4.0 & $0.95-1.24$ & \\
\hline & 5.0 & $1.19-1.56$ & \\
\hline \multirow{3}{*}{ Corn } & 4.0 & $1.28-1.38$ & \multirow{3}{*}{0.94} \\
\hline & 5.0 & $1.61-1.73$ & \\
\hline & 6.0 & $1.93-2.08$ & \\
\hline
\end{tabular}

Source: our calculations.

ing into account the cyclical and risk nature of sugar beet production. The calculation of the cost of bioethanol production from different bioraw materials shows that the most competitive bioethanol production is from molasses.

During 2010-2012, Ukraine saw improvements in tax incentives for the alternative fuels production, in particular, it provided for the exemption from taxation of profits from biofuels producers from the sale of biofuels; the profit of the enterprises received from the activity of simultaneous production of electric and thermal energy with the use of biological fuels; for producers of machinery and equipment produced on the territory of Ukraine for the manufacture and reconstruction of technical and transport vehicles, including self-propelled agricultural machines and power plants that consume biological fuels, an excise tax on the production of biological species was provided at a zero rate for fuel of motor and on the share of fuel, which is a biocomponent in mixed fuel types of motor. On the basis of government decisions taken during the years 2013-2014 , exemptions from the corporate income tax for renewable energy for producers were abolished, exemptions from the value-added tax on biofuel sales, the imposition of high excise taxes on the production of liquid biofuels (introduced in 2013 the excise tax on biodiesel would be EUR 46/t, and from 01.01.2015 - EUR 102/t), the tax burden for fuel producers with the addition of biosolids increased. In general, changes in legislation on the legal regulation of taxation for alternative biofuels producers were unjustified and led to a reduction in liquid fuels. In particular, biodiesel production in Ukraine since 2013 has almost completely ceased, and bioethanol production has decreased significantly. If in 2013 the volume of bioethanol production increased by 2.1 times 
compared to the indicators of 2012, then during 2014 production volumes of this type decreased by 3.7 times compared to $2013^{7}$.

\section{Conclusions}

In the conditions of growing problem of our country ensuring of affordable by the price of energy carriers is appropriate the production of alternative fuels expedite, including production of plant growing. Production and use of biofuels will accelerate the solution of the following strategic objectives for the development of Ukraine, in particular agriculture as reduce dependence of producers on imported fuel and satisfaction of demand for these products at a lower price providing. Therefore it is necessary to ensure of appropriate raw base for bioenergy development - area sown of rapeseed for biodiesel production and sugar beet - for bioethanol optimize. Production and use of bioethanol and biodiesel will establish the production an environmentally clean alternative fuel, new jobs create, profits increase, and Ukraine's dependence on imported fuel reduce. Therefore, the effective functioning of the market development for alternative fuels in Ukraine involves the use of incentive taxation in the industry, which will increase the competitiveness of biofuel producers, and create the investment attractiveness of the industry.

\section{References}

Basic economic indicators of agricultural production in agricultural enterprises, Statistical Bulletin of the year of 2008, State Statistics Committee of Ukraine, Kyiv 2009.

Basic economic indicators of agricultural production in agricultural enterprises, Statistical Bulletin of the year of 2010, State Statistics Committee of Ukraine, Kyiv 2011.

Basic economic indicators of agricultural production in agricultural enterprises, Statistical Bulletin of the year of 2012, State Statistics Committee of Ukraine, Kyiv 2013.

Basic economic indicators of agricultural production in agricultural enterprises, Statistical Bulletin of the year of 2013, State Statistics Committee of Ukraine, Kyiv 2014.

Basic economic indicators of agricultural production in agricultural enterprises, Statistical Bulletin of the year of 2014, State Statistics Committee of Ukraine, Kyiv 2015.

Basic economic indicators of agricultural production in agricultural enterprises, Statistical Bulletin of the year of 2015, State Statistics Committee of Ukraine, Kyiv 2016.

Basic economic indicators of agricultural production in agricultural enterprises, Statistical Bulletin of the year of 2016, State Statistics Committee of Ukraine, Kyiv 2017.

Plant growing of Ukraine, Statistical Digest of the year of 2005, State Statistics Committee of Ukraine, Kyiv 2006.

Plant growing of Ukraine, Statistical Digest of the year of 2015, State Statistics Committee of Ukraine, Kyiv 2016.

\footnotetext{
${ }^{7}$ The results of the analysis of the state of administration of tax privileges granted to economic entities operating in the field of production of alternative fuels and their impact on the state budget revenues, Decision of the Accounting Chamber dated 22 September 2015 No. 5-3, http://zakon.rada.gov.ua/ rada/show/en/vr5-3150-15/sp:max100.
} 
The results of the analysis of the state of administration of tax privileges granted to economic entities operating in the field of production of alternative fuels and their impact on the state budget revenues, Decision of the Accounting Chamber dated 22 September 2015 No. 5-3, http://zakon. rada.gov.ua/rada/show/en/vr5-3150-15/sp:max100.

The results of the final accounting of agricultural sown areas for the harvest of the year of 2001, Statistical Bulletin, State Statistics Committee of Ukraine, Kyiv 2001.

The results of the final accounting of agricultural sown areas for the harvest of the year of 2005, Statistical Bulletin, State Statistics Committee of Ukraine, Kyiv 2005.

Sown areas of agricultural crops under the harvest of the year of 2001, Statistical Bulletin, State Statistics Committee of Ukraine, Kyiv 2001.

Sown areas of agricultural crops under the harvest of the year of 2015, Statistical Bulletin, State Statistics Committee of Ukraine, Kyiv 2015.

Sown areas of agricultural crops under the harvest of the year of 2016, Statistical Bulletin, State Statistics Committee of Ukraine, Kyiv 2016. 